\title{
A novel mycovirus evokes transcriptional rewiring in the fungus Malassezia and stimulates interferon- $\beta$ production in macrophages
}

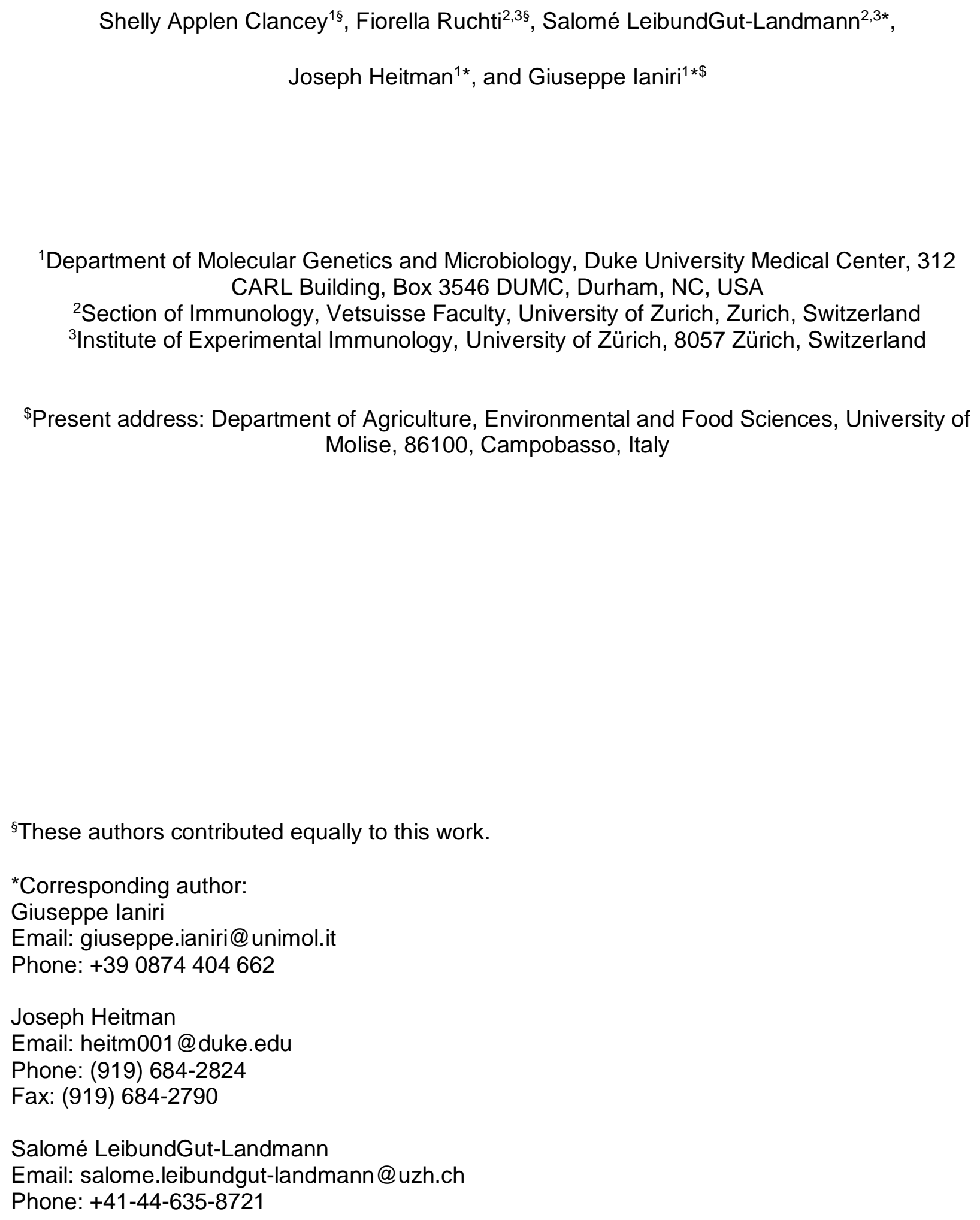

$\S$ These authors contributed equally to this work.

${ }^{*}$ Corresponding author:

Giuseppe laniri

Email: giuseppe.ianiri@unimol.it

Phone: +390874 404662

Joseph Heitman

Email: heitm001@duke.edu

Phone: (919) 684-2824

Fax: (919) 684-2790

Salomé LeibundGut-Landmann

Email: salome.leibundgut-landmann@uzh.ch

Phone: +41-44-635-8721 


\section{Abstract}

Mycoviruses infect fungi, and while most persist asymptomatically, there are examples of mycoviruses having both beneficial and detrimental effects on their host. Virus-infected Saccharomyces and Ustilago strains exhibit a killer phenotype conferring a growth advantage over uninfected strains and other competing yeast species, whereas hypovirus-infected Cryphonectria parasitica displays defects in growth, sporulation, and virulence. In this study we identify a dsRNA mycovirus in five Malassezia species. Sequence analysis reveals it to be a totivirus with two dsRNA segments: a larger $4.5 \mathrm{~kb}$ segment with genes encoding components for viral replication and maintenance, and a smaller $1.4 \mathrm{~kb}$ segment encoding a novel protein. Furthermore, RNA-seq of virus-infected versus virus-cured Malassezia sympodialis revealed an upregulation of dozens of ribosomal components in the cell, suggesting the virus modifies the transcriptional and translational landscapes of the cell. Given that Malassezia is the most abundant fungus on human skin, we assessed the impact of the mycovirus in a murine epicutaneous infection model. Although infection with virus-infected strains was not associated with an increased inflammatory response, we did observe enhanced skin colonization in one of two virus-infected $M$. sympodialis strains. Noteworthy, interferon- $\beta$ expression was significantly upregulated in bone marrow-derived macrophages when challenged with virus-infected, compared to virus-cured M. sympodialis, suggesting that the presence of the virus can induce an immunological response. Although many recent studies have illuminated how widespread mycoviruses are, there are relatively few in-depth studies about their impact on disease caused by the host fungus. We describe here a novel mycovirus in Malassezia and its possible implications in pathogenicity.

\section{Importance}

Malassezia species represent the most common fungal inhabitant of the mammalian skin microbiome, and are natural skin commensal flora. However, these fungi are also 
bioRxiv preprint doi: https://doi.org/10.1101/2019.12.18.880518; this version posted June 11,2020. The copyright holder for this preprint

(which was not certified by peer review) is the author/funder, who has granted bioRxiv a license to display the preprint in perpetuity. It is made available under aCC-BY-NC-ND 4.0 International license.

72 associated with a variety of clinical skin disorders. Recent studies have reported associations of

73 Malassezia with Crohn's disease and pancreatic cancer, further implicating this fungal genus in

74 inflammatory and neoplastic disease states. Because M. sympodialis has lost genes involved in

75 RNAi, we hypothesized Malassezia could harbor dsRNA mycoviruses. Indeed, we identified a

76 novel mycovirus of the totivirus family in several Malassezia species, and characterized the

77 MsMV1 mycovirus of M. sympodialis. We found conditions that lead to curing of the virus, and

78 analyzed isogenic virus-infected/virus-cured strains to determine MsMV1 genetic and

79 pathogenic impacts. MsMV1 induces a strong overexpression of transcription factors and

80 ribosomal genes, while downregulating cellular metabolism. Moreover, MsMV1 induced a

81 significantly higher level of interferon- $\beta$ expression in cultured macrophages. This study sheds

82 light on the mechanisms of pathogenicity of Malassezia, focusing on a previously unidentified

83 novel mycovirus. 


\section{Introduction}

Viruses are widely distributed in nature and are found in a variety of hosts, ranging from single-celled organisms to plants and mammals. The presence of mycoviruses, viruses that infect fungi, can be benign but are also associated with toxin secretion in yeast, hypovirulence in pathogenic plant fungi, and hypervirulence in dimorphic fungi (1-5). Mycoviruses are typically composed of double-stranded RNA (dsRNA) genomes, but positive-sense and negative-sense single-stranded RNA viruses, as well as circular ssDNA viruses have been reported to infect fungi (6). Overall, more than 10 different families of viruses have been isolated from fungal hosts (7). Despite similar genomic features shared between mycoviruses and human viruses from the same family, one clear difference between the two is the absence of cell-to-cell transmission proteins in mycoviruses. Therefore, mycoviruses typically lack an extracellular stage and are only transmitted during cell division, or by cell or hyphal fusion (8-10).

A well-known example of a mycovirus is the killer virus of Saccharomyces cerevisiae. This toxin-producing dsRNA virus was characterized in the 1970s (11), and found to have two dsRNA segments: a larger, $4.5 \mathrm{~kb}$ dsRNA, and a smaller, $1.5 \mathrm{~kb}$ satellite dsRNA. The large segment, called L-A, is required for viral replication and maintenance. The smaller segment, called $\mathrm{M}$, encodes a pre-protoxin, which is processed into a mature toxin by host enzymes and then secreted from the cell $(12,13)$. During the replication cycle of $L-A$, the single-stranded positive-strand $[(+)$ ssRNA] is transcribed by the virally encoded replication machinery and released from the virion to serve two roles; 1 ) it is the mRNA template for translation of the Gag and Gag-Pol fusion protein, and 2) it is the template that is packaged into new viral particles where transcription reoccurs $(13,14)$. Yeast cells harboring both the L-A and M dsRNA segments display a growth advantage over strains lacking these components. When toxinproducing strains compete with wild-type strains, the virus-infected strains secrete the mature killer toxin, killing neighboring cells, whereas the toxin-producing cells remain unharmed (15). A similar fitness advantage is conferred by toxin-producing strains of Ustilago maydis (2). 
In contrast to the killer viruses that provide virus-infected strains a growth advantage, the

111 mycovirus that infects Cryphonectria parasitica, the causative agent of chestnut blight (which

112 decimated the population of chestnut trees in the United States in the early 1900s by killing

113 more than one billion trees) impairs growth of the fungus $(16,17)$. The growth defect of virus-

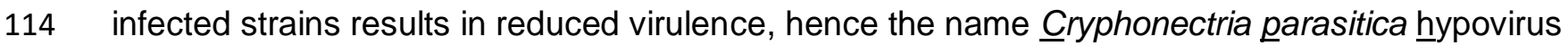

115 (CHV). Five different viral segments isolated from C. parasitica have been shown to confer a

116 high level of hypovirulence, although the level of impact on fungal growth observed in the

117 infected fungal strain appears to be virus strain-dependent $(16,18)$. A mycovirus infecting the

118 filamentous fungus Pseudogymnoascus destructans has also been implicated in the

119 epidemiology of white-nose syndrome, a lethal fungal infection in bats, as bats in North America

120 have experienced 5 million deaths in the past decade, and all $P$. destructans isolates from bats

121 in this region harbor a mycovirus (19). This is compared to European and Asian P. destructans

122 isolates, which do not harbor the mycovirus, and the resident bat populations appear to be

123 resistant to the endemic fungus.

124 RNAi is an important pathway conserved in many organisms and serves to regulate

125 gene expression, suppress transposon movement, and maintain genome integrity. Additionally,

126 a functional RNAi pathway has been shown to suppress mycovirus proliferation $(20,21)$. The

127 biogenesis of small RNAs (sRNAs) originating from the infecting virus (termed virus-derived

128 small interfering RNAs, or vsiRNAs) is analogous to that of endogenous sRNAs, requiring

129 essential components such as dicer ( $D C L)$, argonaute $(A G O)$, and RNA-dependent RNA

130 polymerase $(R D P)(22)$. It was previously thought that mycoviruses might only survive in

131 species that lack a functional RNAi pathway as introduction of argonaute and dicer into yeast

132 resulted in the elimination of the mycovirus (20). To this end, fungal species lacking canonical

133 RNAi pathways have been good candidates in which to screen for mycoviruses. However,

134 increased research on mycoviruses over the past decade has produced reports showing that

135 mycoviruses have developed strategies to counteract the RNAi defense mechanisms that 
suppress antiviral activity (5). In Aspergillus nidulans, infection of conidia with Virus 1816 suppresses inverted repeat transgene (IRT)-induced RNA silencing, and when the virus was cleared from ascospores, IRT silencing was restored (23). Other examples of mycovirusinduced RNAi suppression in C. parasitica and Rosellinia necatrix involve viral targeting of the RNAi machinery. In the case of $C$. parasitica, CHV1-EP713 encodes a papain-like protease (p29) that suppresses hairpin RNA-triggered silencing in the fungus (24). In $R$. necatrix, the mycoreovirus RnMyRV3 s10 gene encodes a product that appears to suppress RNA silencing by interfering with the dicing of dsRNA (25). Most recently, a novel partitivirus, TmPV1, was identified in Talaromyces marneffei, and is correlated with the downregulation of the $d c l-1, d c l-2$, and qde-2 RNAi genes in both virus-infected yeast and mycelia (4). Examples of virus-induced RNAi suppression spanning multiple classes of fungi is evidence that RNAi functions to control viral levels and that mycoviruses have evolved ways to counteract this regulation.

The genus Malassezia is a monophyletic group of lipophilic yeasts that colonize sebaceous skin sites and represent more than $90 \%$ of the skin mycobiome. Despite being a commensal yeast, Malassezia is associated with a number of common skin disorders, such as seborrheic dermatitis, atopic eczema, pityriasis versicolor, and also systemic infections (26). Recently, two landmark studies reported the association of Malassezia with gastrointestinal disorders such as Crohn's disease in a subset of patients with CARD9 mutations (which enhance sensitivity to fungal pathogen-associated molecular patterns [PAMPs]) and pancreatic cancer $(27,28)$, highlighting the importance of this understudied fungal genus as a crucial component of the human mycobiome. All Malassezia species lack the fatty acid synthase gene and thus are lipid-dependent, relying on exogenous fatty acids for growth. This feature makes Malassezia unique and fastidious to study under laboratory conditions, and as consequence relatively limited research has been done on the basic biology of this organism.

To date, 18 different species of Malassezia have been identified and sequence for 15 of these genomes is publicly available. Of these, the M. sympodialis ATCC42132 genome is the 
162

163

164

165

166

167

168

169

170

171

172

173

174

175

176

177

178

179

180

181

182

183

184

185

186

most well annotated reference genome based on whole genome sequencing, RNA-seq, and proteomics $(29,30)$. As commensal inhabitants of the skin, Malassezia yeasts interact with the skin immune system, and specific T cells, as well as IgG and IgM antibodies, can be detected in healthy individuals, whereas specific $\lg \mathrm{E}$ antibodies are prevalent in a large proportion of patients suffering from atopic eczema. A number of molecules with immunoglobulin $E(\lg E)$ binding capabilities have been identified in extracts of Malassezia and have been named MalaS allergens. Ten allergens have been identified in $M$. sympodialis, and three in $M$. furfur. Eight of these allergens are conserved proteins that share high similarity with the corresponding mammalian homolog, suggesting that the induction of autoreactive T cells by Malassezia allergens could play a role in sustained inflammation $(26,31)$. Nevertheless, both the fungal and host factors contributing to the transition of Malassezia from commensal to pathogen are unknown and this is an active area of research.

Malassezia has a relatively small genome of $7.7 \mathrm{Mb}$, and due to its reduced size has lost nearly 800 genes compared to other sequenced Basidiomycota, including genes of the RNAi pathway (29). Given that Malassezia has lost the RNAi machinery, we hypothesized it could harbor mycoviruses and screened our collection of Malassezia strains for novel dsRNA viruses. Here, we report the discovery of a novel mycovirus from M. sympodialis, MsMV1. Following the screening of three dozen $M$. sympodialis isolates in our collection, we observed that this mycovirus is present in approximately $25 \%$ of the isolates. Fungal cells can be cured of the mycovirus upon exposure to high temperature or the antimicrobial agent biphenyl. RNA sequencing of infected and cured strain pairs revealed the complete genome of MsMV1 and illuminated a large shift in the cellular transcriptional profile comparing the congenic virusinfected and virus-cured strains. The presence of MsMV1 correlated with an increased ability to colonize skin in one of two cases tested, and increased production of interferon- $\beta$ in cultured macrophages was associated with all virus-infected strains tested. These findings reveal a novel 
bioRxiv preprint doi: https://doi.org/10.1101/2019.12.18.880518; this version posted June 11, 2020. The copyright holder for this preprint (which was not certified by peer review) is the author/funder, who has granted bioRxiv a license to display the preprint in perpetuity. It is made available under aCC-BY-NC-ND 4.0 International license.

187 mycovirus harbored by Malassezia with possible implications for interactions with the host in 188 both the commensal and disease states. 


\section{Results}

\section{Identification and characterization of a novel mycovirus in Malassezia}

Whole genome sequencing revealed that the Malassezia species have lost the genes required for a functional RNAi pathway (29); therefore, we hypothesized the fungus had the capacity to harbor mycoviruses. Following the screening of M. sympodialis, M. pachydermatis, and $M$. furfur laboratory freezer stocks, dsRNA species were detected in 11 of $36 \mathrm{M}$. sympodialis isolates (30.5\%), one of three $M$. pachydermatis isolates (33.3\%), and no $M$. furfur isolates. dsRNA species were also found in one of two M. globosa isolates, one M. obtusa isolate, and one M. yamatoensis isolate (Figure 1A, 1B, and Figure S1). For M. sympodialis, two dsRNA segments were visualized on an ethidium bromide-stained agarose gels, one at $\sim 4.5 \mathrm{~kb}$ and another at $\sim 1.4 \mathrm{~kb}$. The sizes of these dsRNA segments are similar to those found in $S$. cerevisiae strains that produce killer toxins (1), suggesting the segments may correspond to a helper virus and a satellite RNA encoding a toxin precursor. M. obtusa and $M$. yamatoensis appear to only have the larger $\sim 4.5 \mathrm{~kb}$ species as no dsRNA species of $\sim 1.4 \mathrm{~kb}$ was detected. M. globosa also has a $\sim 4.5 \mathrm{~kb}$ dsRNA species as well as two smaller species of $\sim 500 \mathrm{bp}$ and 600 bp (Figure 1B).

In the present study we focused on the characterization of the mycovirus of $M$. sympodialis as a representative species of the Malassezia genus. To unveil the biological and physiological roles of the putative Malassezia mycovirus, a crucial first step was to define conditions that allow elimination (i.e. curing) of the mycovirus. In other fungi, mycoviruses can be cured by exposure to stressful conditions or certain drugs. In S. cerevisiae, exposure to the fungicide cycloheximide cures killer cells of the killer phenotype (32). This has varying rates of success in other organisms, such as Aspergillus, where a less than $50 \%$ success rate of mycovirus curing was observed after exposure to cycloheximide (33). In filamentous fungi, conidial isolation and hyphal tipping are more commonly used methods for curing (33), and polyethylene glycol was shown to cure $P$. destructans of PdPV-pa infection (19). To determine if 
M. sympodialis could be cured of the dsRNA, the strains were passaged on modified Dixon's (mDixon) media and subjected to various stresses. We found that six passages on mDixon medium with no additives at high temperature $\left(37^{\circ} \mathrm{C}\right)$ resulted in a complete loss of both dsRNA segments in four M. sympodialis virus-infected strains (Figure 1C, middle section). Following a single passage on mDixon medium with $10 \mu \mathrm{g} / \mathrm{mL}$ biphenyl, strains SEC555 and SEC557 derived from KS013 and KS016, respectively, lost both dsRNA species, while strains SEC554 and SEC558 (derived from KS012 and KS017, respectively) retained both dsRNA species (Figure 1C, right section). All dsRNA containing strains retained both segments when passaged on mDixon with no additives at $30^{\circ} \mathrm{C}$ (Figure $1 \mathrm{C}$, left section).

To determine if the dsRNA moieties isolated from M. sympodialis are of viral origin, the dsRNA molecules of M. sympodialis were converted to cDNA and subjected to TA-cloning and Sanger sequencing. Clones of the large moiety were obtained from strain KS013, and from KS012 for the smaller one. Primer walking with Sanger sequencing revealed only partial insertions of the two into the cloning plasmid: a $1.3 \mathrm{~kb}$ region of the large $\sim 4.5 \mathrm{~kb}$ segment, and a $374 \mathrm{bp}$ portion of the $\sim 1.4 \mathrm{~kb}$ segment. Blastx of the $1.3 \mathrm{~kb}$ sequence derived from the larger dsRNA revealed similarities with other mycoviruses deposited in GenBank, while a blastx search of 374 bp sequence derived from the smaller dsRNA found no hit (see later in the text for details). In parallel with the cDNA synthesis, cloning and sequencing, the congenic virusinfected and virus-cured strains KS012 and SEC494 of M. sympodialis were subjected to ribosomal RNA-depleted RNA sequencing. The rationale of the RNA-seq analysis was two-fold; first, allowing a more facile identification of the entire viral genome and second, elucidating possible transcriptomic changes evoked by the mycovirus in the host cells.

For the identification of the viral genome, adaptor-free RNAseq reads derived from $M$. sympodialis virus-infected and virus-cured isolates were assembled with Trinity. The resulting transcripts were searched using the sequences previously obtained through TA-cloning as a query, and two perfect hits ( $E$ value 0.0$)$ were obtained following a blastn search against the 
241 virus-infected strain KS012. Both hits are part of two larger independent contigs (DN8321 of

$2424613 \mathrm{bp}$, and DN4986 of $4601 \mathrm{bp}$; see File S1 legend for details) that subsequent analyses

243 (described in detail below) reveal represent the entire viral genome. The two identified contigs

244 are identical with the exception of a few nucleotides located at the sequence extremities and

245 outside coding regions, likely being residual adaptor or assembly artifacts (File S1). Conversely,

246 blastn analysis of the $1.3 \mathrm{~kb}$ viral TA-cloned sequence against the transcriptome of the virus-

247 cured isolate SEC494 found only a small 308 bp hit ( $E$ value 1e-143) that is part of the $M$.

248 sympodialis ATCC42132 MRP4 ortholog, which encodes a mitochondrial ribosomal protein of

249 the small subunit (MSYG_4110, accession SHO79760). Combined with nucleic acid analysis

250 based on agarose-ethidium bromide stained gels, this sequencing further supports that the

251

252

253

254

255

256

257

258

259

260

261

262

263

264

265

266 dsRNA had been completely eliminated in the virus-cured strain.

Moreover, PCR analyses with primers designed to specific regions of the large and small dsRNA segments failed to produce amplicons on M. sympodialis KS012 genomic DNA, suggesting that the viral sequence is not integrated in the genome but is rather cytoplasmic.

This finding is corroborated by in silico BLAST searches that failed to detect either large or small segment viral sequences in the de novo genome assembly of $M$. sympodialis KS012 (described below).

Using the ExPASy Translate web tool, the $4.6 \mathrm{~kb}$ segment was found to contain two open reading frames (ORFs), distinguished by a -1 ribosomal frameshift, a common feature of totiviruses (Figure 2A) (34). A BLASTp search of the ORF produced by a frame 1 translation revealed the RNA-dependent RNA polymerase gene $(R D P)$ from Scheffersomyces segobiensis virus $L$ (SsV L) with $52.69 \%$ homology. A BLASTp search of the ORF produced by a frame 2 translation identified the capsid protein from the same $S$. segobiensis virus, in this case with $53.87 \%$ homology (35). Phylogenetic analysis of the Rdp1 sequence obtained from RNA-seq grouped it with Rdp1 sequences from other mycoviruses of the totiviridae family (Figure 2B). Moreover, bidirectional blast analysis using the S. segobiensis SsV L virus genome as a query 
against the M. sympodialis KS012 transcriptome assembly found the contigs DN8321 and DN4986 (File S1). These results strongly support that the large dsRNA segment isolated from M. sympodialis is a novel mycovirus and encodes proteins required for mycoviral replication and maintenance.

Similarly, the 374 bp query sequence from the smaller dsRNA segment identified via TAcloning was subjected to a blastn search against the assembled transcriptomes of the virusinfected and virus-cured M. sympodialis strains KS012 and SEC494, respectively. Two highly significant hits ( $E$ value $3 e-170$ and $2 \mathrm{e}-166)$ were obtained only against the genome of the virus-infected strain KS012. The two hits are part of two independent contigs (DN7179 of 1546 bp and DN6052 of $1479 \mathrm{bp}$; see File S2 legend for details), consistent with the size of the small dsRNA segment based on agarose gel electrophoresis. These contigs are identical with the exception of a few nucleotides located at the sequence extremities and outside coding regions (File S2). Translation of this contig showed a single ORF (Figure 2C), which when used in a BLASTp search in NCBI returned only weak ( $\leq 29 \%$ homology, $E$ value $\geq 1.6$ ) hits to the 3 ' region of uncharacterized and hypothetical proteins in Sporisorium reilianum and Streptomyces, respectively; no significant hits were obtained from NCBI for the small segment.

To infer the function of this virally-encoded protein, the predicted amino acid sequence was subjected to domain prediction using Interpro Scan. A 305 amino acid non-cytoplasmic domain was identified at the C-terminal end of the protein and a short 19 amino acid signal peptide is predicted at the $\mathrm{N}$-terminus (Figure 2D). Signal peptides are commonly present at the $\mathrm{N}$-terminus of proteins that are destined for secretion. Signal peptides are composed of three regions: an $\mathrm{N}$-region, an $\mathrm{H}$-region, and a C-region. Typically, the $\mathrm{N}$-region contains a stretch of positively charged amino acids, the $\mathrm{H}$-region is the core of the signal peptide that contains a stretch of hydrophobic amino acids, and the C-region contains a stretch of amino acids that are recognized and cleaved by signal peptidases (36). The presence of this signal peptide, and the lack of homology to any protein in the NCBI database, suggests the $\sim 1.5 \mathrm{~kb}$ dsRNA segment 
from M. sympodialis encodes a previously unidentified, novel protein of unknown function that is likely secreted from the cell. Given the data supporting that these dsRNA segments represent a dsRNA virus in M. sympodialis, we termed this virus MsMV1 (ㅆalassezia sympodialis $\underline{\text { mycovirus }}$ 1).

\section{MsMV1 infection causes an upregulation of a large number of ribosomal genes}

As described, total RNA from congenic virus-infected and virus-cured strain pairs KS012 and SEC494 was subjected to analysis of differentially expressed genes in the virus-infected strain compared to its cured counterpart. For RNA-seq analysis, three biological replicates of each sample were analyzed. RNA-seq reads of virus-infected and virus-cured strains KS012 and SEC494 were mapped against the reference M. sympodialis genome ATCC42132 using HiSat2. Transcript abundance was estimated through StringTie, and differentially expressed genes with a false discovery rate $(F D R)<0.05$ and a $\log _{2}$-fold change $+/-1$ were identified with EdgeR $(37,38)$.

The virus-infected strain displayed differential expression of 172 genes in comparison to the virus-cured strain, with 89 genes being upregulated $\left(\log _{2}\right.$-fold change between 1 and 8.14$)$ and 83 genes being downregulated ( $\log _{2}$-fold change between -1 and -4.6) (Figure 3A). Among the proteins differentially upregulated, $~ 50 \%$ are involved in ribosomal biogenesis and translation (Figure 3B). The remaining genes are involved in DNA replication and maintenance, transcription, stress responses, and other cellular metabolic processes. The most highly upregulated gene in the virus-infected strain, with a $\log _{2}$-fold change of 8.14 , was MSYG_3592, encodes an uncharacterized mediator complex protein. The mediator complex is a transcriptional coactivator that interacts with transcription factors and RNA polymerase II, which transcribes all protein-coding and most non-coding RNA genes (39). The change in expression of this gene, combined with the upregulation of phosphorylation activity, ribosomal biogenesis, and cytoplasmic translation, indicates a large transcriptional shift in the virus-infected strain. 
Downregulated genes included those involved in metabolic processes, oxidation-reduction processes, transmembrane transport, cell cycle and cell division, and many uncharacterized transcripts. In particular, the most downregulated gene that passed the FDR $<0.05$ threshold with a $\log _{2}$-fold change of -4.6 is an endoplasmic reticulum (ER) membrane protein, MSYG_1988, a gene whose predicted product is involved in the movement of substances

323 across the ER membrane and/or protein synthesis. The second most downregulated gene is

324 MSYG_0220 ( $\log _{2}$-fold change $\left.=-4.1\right)$, which is an ortholog of $S$. cerevisiae CDC39. Cdc39 is a

325 component of the Ccr4-Not1 complex that, in addition to its role as a global transcriptional 326 regulator, regulates mRNA decay. These data suggest that elimination of aberrant mRNA 327 transcripts may be inhibited in the virus-infected strain. Interestingly, we identified a gene (MSYG_3324) with the lowest $\log _{2}$-fold change $(-11.88)$ that did not pass the statistically significant threshold of FDR $<0.05$. The gene MSYG_3324 gene encodes a hypothetical protein that has a guanine nucleotide exchange factor domain, leucine-rich repeats of the ribonuclease inhibitor (RI)-like subfamily, and an N-terminal Herpes BLLF1 superfamily domain, which consists of the BLLF1 viral late glycoprotein that is the most abundantly expressed glycoprotein in the viral envelope of the Herpes viruses. Strikingly, BLLF1 represents a major antigen responsible for production of neutralizing viral antibodies in vivo (40), and we speculate that it might be strongly downregulated by the MsMV1 mycovirus as a mechanism to dampen $M$. sympodialis antiviral defense systems. Overall, our RNA-seq dataset is clearly indicative of a 337 significant transcriptional rewiring of $M$. sympodialis in the presence of the dsRNA mycovirus 338 MsMV1.

The three technical replicates of each strain produced highly similar expression profiles, which are distinct from one another (Figure 3C). The largest cluster of upregulated genes in the

341 virus-infected strains included ribosomal components, and a gene network map shows the tight 342 interaction of these ribosomal components (Figure 3D). The large, central cluster consists of 
ribosomal proteins that are regulated by translation initiation factors Anb1 and Rpg1, and also Noc3, which bind ribosomal precursors to mediate their maturation and intranuclear transport. One question that we sought to answer was whether the conditions employed to cure the virus changed the strain in any way other than virus elimination. We generated whole genome Illumina data and then performed genome-wide analyses and SNP calling of the $M$. sympodialis cured strain SEC494, comparing it to the virus-infected strain KS012. Only two nucleotide changes unique to the virus-cured isolate SEC494 were identified. These include mutations in the coding regions of $K A E 1$, an ATPase, and CRM1, a karyopherin responsible for the transport of molecules between the cytoplasm and the nucleus (Table S1, File S3). Being as these mutations were only found in the virus-cured strain, they may be a consequence of the "curing treatment" and we predict their impact on fitness to be minimal given similar growth characteristics of the two strains (Table S1; File S3). Moreover, the assembled KS012 and SEC494 genomes are co-linear with the reference M. sympodialis genome ATCC42132 (Figure S2A-C), and no change in ploidy or aneuploidy was observed for any chromosome (Figure S2D).

\section{Malassezia mycovirus does not impact pathogenicity in an epicutaneous murine model}

In a recent study, Sparber and colleagues described a murine epicutaneous infection model that involves application of Malassezia to the mouse dorsal ear following mild tape stripping (41). Colonization of host tissue (fungal load) is determined by plating homogenized tissue onto agar plates and counting colony forming units; an increase in ear thickness is used as a measurement for skin inflammation. When mice were challenged with congenic virusinfected and virus-cured strains in this model, only the virus-infected strain KS012 displayed increased colonization compared to its virus-cured counterpart, while there was no difference in the other strain pairs tested by day 4 post-infection (Figure S3A). No change in ear thickening (as a readout for inflammation) was observed in response to the virus-infected strains compared 
to their cured counterparts. To control for the temperature exposure in the virus-cured strains, a strain without MsMV1 was passaged at $37^{\circ} \mathrm{C}$. No changes in skin colonization or ear thickening was observed in the heat-treated virus-uninfected counterpart when tested in the epicutancous infection model (Figure S3A). To determine if there was a difference in the immune response elicited by the virus-infected and virus-cured strains, we assessed the expression of interleukin17 (IL-17), a key mediator of the host response against Malassezia on the skin (41). However, we could not detect any statistically significant differences in cytokine induction in response to virus-infected and virus-cured strains (Figure S3C), indicating that IL-17 expression is not regulated by the virus and not responsible for the observed differences in fungal load observed for strain KS012. We also assessed expression of IFN- $\beta$, a central player in antiviral immunity, but could not measure expression above the basal levels detected in the skin of naïve control animals (Figure S3C). The same was also true at earlier or later time points after infection (Figure S3D, E). Similarly, the heat-untreated and heat-treated virus-uninfected control strain did not display differential IL-17 or IFN- $\beta$ expression (Figure S3C).

\section{Virus-infected strains induce interferon- $\beta$ expression in bone marrow-derived}

\section{macrophages in a TLR3-independent manner}

Given its close relationship with the skin, Malassezia primarily interacts with keratinocytes and tissue-resident mononuclear phagocytes, including macrophages. Therefore, we assessed the interaction of $M$. sympodialis virus-infected and virus-cured strains with macrophages. Bone marrow-derived macrophages (BMDMs) are mature, differentiated bone marrow monocyte/macrophage progenitors that are suitable for host-pathogen interaction studies (42). Interferon- $\beta$ (IFN- $\beta$ ) expression in BMDMs was measured by RT-qPCR following incubation with virus-infected and virus-cured $M$. sympodialis strains for 24 hours. The presence of MsMV1 induced significantly more IFN- $\beta$ expression in BMDMs than virus-cured strains (Figure 4A). 
In leishmaniasis, a parasitic disease caused by Leishmania, an elevated burden of

Leishmania RNA virus-1 (LRV1) in the parasite is associated with parasite dissemination and

increased disease severity $(43,44)$. Toll-like receptors (TLRs) are innate immune-recognition

receptors known to play a role in viral infection, and TLR3, which recognizes and responds to

dsRNA (45), was found to be required for the induction of pro-inflammatory factors and disease

exacerbation in leishmaniasis (43). Given the relationship between TLR3 and dsRNA

recognition, TLR3 deficient BMDMs were incubated with the virus-infected and virus-cured

Malassezia strains. In contrast to observations with LRV1, the increased production of IFN- $\beta$ by

MsMV1-infected strains was not dependent upon TLR3, as deletion of this gene in BMDMs did

and TNF expression, was also assessed (Figure S4A). No significant differences were found in

BMDMs incubated with virus-infected and virus-cured $M$. sympodialis strains, and deletion of

TLR3 did not change this result (Figure S4C). The seemingly enhanced induction of CD86 by

407 the virus-cured strain SEC494 (Figure S4A) was not reproducible in independent repeat unlikely to be related to the absence of the virus.

\section{Discussion}

Mycoviruses are proving to be much more ubiquitous in nature than previously

413 appreciated. Fungi harboring mycoviruses display a range of phenotypes, which in some cases

414 can prove beneficial or detrimental for the host plant or animal. For instance, C. parasitica

415 carries the CHV1 virus that causes reduced growth and pathogenicity of the fungus. Therefore,

416 trees infected with virus-infected strains of $C$. parasitica display smaller cankers than trees

417 infected with virus-free strains (16). Application of hypovirus-infected strains to cankers has 
418

419

420

421

422

423

424

425

426

427

428

429

430

431

432

433

434

435

436

437

438

439

440

441

442

443

proven to be an effective biocontrol agent as it halted the decimation of the chestnut tree in North America (17). Conversely, virus-infected L. guyanesis exacerbates leshmaniasis in mice and increases parasitemia, leading to the dissemination and metastasis of the parasite from the infection site (43).

Here, we describe the discovery of dsRNA mycoviruses in five Malassezia species: $M$. sympodialis, M. pachydermatis, M. globosa, M. obtusa, and M. yamatoensis (Figure 1A, 1B, and Figure S1), and characterize in detail the MsMV1 virus from M. sympodialis. RNA-sequencing revealed the large dsRNA segment from $M$. sympodialis is of viral origin and contains two open reading frames that encode the Rdp1 and capsid proteins, which are translated by a -1 ribosomal frameshift, a hallmark feature of the Totiviridae virus family (Figure 2A)(34). Accordingly, phylogenetic analysis of the Rdp1 open reading frame groups most closely with other mycoviruses from the totiviridae family (Figure $2 \mathrm{~B}$ ). Using the small dsRNA segment sequence as a query, no significant matches were found in the NCBI database, suggesting the satellite virus is unique to this fungus and could serve a specialized role. Taken together, these data support the discovery of a novel mycovirus in the important skin fungus $M$. sympodialis. Further investigation will be required to characterize the presumptive mycoviruses in the other Malassezia species.

We find that exposure to high temperature $\left(37^{\circ} \mathrm{C}\right)$ or to an antimicrobial agent (biphenyl) cures M. sympodialis of MsMV1 (Figure 1C). These are two conditions frequently encountered by fungi. Systemic human patient fungal isolates are exposed to high temperature during infection, and isolates from both patients and the environment are often purified on media containing antimicrobials to inhibit bacterial or filamentous fungal growth from the host or environment. It is possible these typical microbiological isolation methods may be inducing mycovirus curing during isolation. Taken together with the growing reports on their discovery of novel mycoviruses, mycoviruses may be much more abundant than currently appreciated. Not all of the Malassezia isolates analyzed in this study harbored a mycovirus, and this could reflect 
444

445

446

447

448

449

450

451

452

453

454

455

456

457

458

459

460

461

462

463

464

465

466

467

468

469

either natural diversity or curing during isolation. It is not clear why these two conditions cause

virus curing. In the case of high temperature, this stressful condition may alter cellular

physiology rendering the cell a less favorable host for the mycovirus. Viral replication and

maintenance, while neutral at $30^{\circ} \mathrm{C}$, could interfere with cellular processes required for survival

at $37^{\circ} \mathrm{C}$. Moreover, high temperature is known to increase heat shock and misfolded proteins in

the cell (46), and if full Hsp90 function is required for viral replication then the virus could be lost due to the overburdened Hsp90.

RNA-sequencing of virus-infected and virus-cured strains revealed major differences in the transcriptional profile between the two strains. Most notably is the upregulation of a large number of ribosomal components in the virus-infected strains, suggesting an increased translational activity induced by the mycovirus. A similar result was found with the plant fungus Sclerotinia sclerotiorum, which harbors the SsHV2-L hypovirus, where rRNA metabolic processes and cellular component biogenesis were the classes of the most upregulated genes in virus-infected strains (47). Alternatively, the opposite has been observed in S. cerevisiae, where virus-infection is associated with the down-regulation of ribosome biogenesis and stress response, suggesting that in $S$. cerevisiae, virus-infected cells may be less stressed due to host protection systems for the killer virus (48).

Genes involved in oxidation-reduction processes are another category that was downregulated in the virus-infected strain. Denitrification, the biological process of converting nitrate to ammonia through reduction, which is then broken down into nitrogen, nitrous oxide, and nitric oxide (NO), is an important pathway in living organisms. NO is an important signaling molecule in bacteria and fungi. Furthermore, NO production is positively correlated with aflatoxin production in $A$. nidulans, where deletion of flavohemoglobin, a nitric oxide reductase, leads to reduced sterigmatocystin production and afIR expression (49). Flavohemoglobin, encoded for by the $Y H B 1$ gene in $M$. sympodialis, does not appear to play a role in putative toxin producing strains as it is downregulated only 0.69-fold in MsMV1-infected strains. Recent work from 
Wisecaver and colleagues as well as our lab has identified that Malassezia acquired

471 flavohemoglobin via a horizontal gene transfer event from Actinobacteria $(49,50)$. A likely

472 explanation for the difference in the role of flavohemoglobin between $A$. nidulans is because the

473 gene was not endogenous to Malassezia and rather acquired from an exogenous bacterial

474 source, and therefore may not have been adapted to play a regulatory role with the virus. The

475 presence of the virus may be inducing the upregulation of transcriptional and translational

476 machinery in order to synthesize components required for viral replication, maintenance, and

477 persistence. Analysis of gene expression in additional virus-infected strains as well as virus-

478 uninfected strains would further confirm the gene expression changes imparted by the virus.

479 How this signal is translated from the virus to the fungus is an interesting area for future research.

RNAi is a common antiviral defense system that operates in fungi to combat viral significantly downregulated gene is involved in mRNA decay, MSYG_0220 (CDC39). As

490 described earlier, during the virus replication cycle, a ssRNA intermediate is formed prior to

491 virion assembly (13) and is vulnerable to fungal defense mechanisms. Suppressing the

492 expression of genes involved in eliminating anomalous mRNA transcripts could be a strategy for

493 the virus to survive in the fungal cell. Interestingly, the RNA-seq analysis identified the

494 downregulation of MSYG_03961 (CPR3) in virus-infected M. sympodialis cells. CPR3 is a gene

495 that encodes a mitochondrial cyclophilin (53) that could be linked to pathogenesis via 
established roles of mitochondria in basidiomycete pathogens (54). Although the passing at high

497 temperature did not induce many genomic changes, it is possible epigenetic changes occurred

498 during the treatment that resulted in changes in gene expression, and further studies are

499 needed to address this question.

Mycoviruses impact fungal virulence in different ways. Mycoviruses can be

501 asymptomatic, whereas others induce either a hypo- or hyper-virulent state in the host fungus.

502 We employed a recently developed murine model for Malassezia in which the fungus is applied

503 onto the mouse ear following mild barrier disruption to replicate hallmarks of atopic dermatitis

504 (41). We found one of two virus-infected strains that displayed an enhanced ability to colonize

505 the murine skin, compared to its virus-cured counterpart, but did not observed any differences in

506 inflammation or cytokine production (Figure S3A, B, and C). Promisingly, cultured macrophages

507 responded differently to virus-infected and virus-cured strains in which more IFN- $\beta$ was

508 produced from BMDMs incubated with virus-infected strains than virus-cured strains (Figure

509 4A). Other parameters such as BMDM viability and BMDM activation were measured in parallel

510 and no difference was detected between virus-infected and virus-cured strains (Figure S4A).

511 We conclude that under certain circumstances, MsMV1 appears to provide an enhanced ability

512 to colonize skin, and increased IFN- $\beta$ in cultured macrophages is a common characteristic of all

513 virus-infected strains tested, thus suggesting some role in the pathogenicity of $M$. sympodialis.

514 However, the degree to which the virus plays a role is still uncertain. It is possible characteristics

515 in the genomic background of the M. sympodialis virus-infected strain influences the degree to

516 which the virus exacerbates disease. Perhaps there are features of the KS013 genome that

517 allow it to better control viral load of MsMV1 and so it does not impart the same growth

518 advantage on the skin. As KS012 was the only virus-infected genome sequenced in this study

519 we do not know if there are any differences between it and KS013 that would account for the

520 differences observed in skin colonization experiments. 
Due to the role of IFN- $\beta$ in the stimulation of antiviral and antiproliferative products (55),

522 it is possible that the production of IFN- $\beta$ may lead to enhanced clearing of virus-infected fungal

523 cells from macrophages. TLR3 binds dsRNA in mammalian cells and was shown to play a

524 critical role in disease exacerbation in leishmaniasis when the infecting Leishmania strain

525 harbors a mycovirus $(43,44)$. In the case of $M$. sympodialis, we did not observe a requirement

526 of TLR3 for IFN- $\beta$ production in response to virus-infected strains (Figure 4B). We posit that

527 dsRNA recognition by Malassezia may occur through an alternative virus recognition pathway

528 yet to be elucidated that may recognize mycoviral dsRNA as a fungal pathogen-associated

529 molecular pattern (PAMP).

In conclusion, we report for the first time evidence of mycoviruses infecting the fungal genus Malassezia. Although the target of the putative satellite toxin is unknown, it induces an

532 immune response in macrophages. Co-incubation of the virus-infected $M$. sympodialis with

533 virus-cured M. sympodialis and bacterial species (Escherichia coli, Corynebacterium spp., and

534 Staphylococcus spp.) failed to reveal antifungal or antibacterial properties of the virus-infected

535 M. sympodialis strains. Determining if changes in the expression of metabolic genes in the

536 virus-infected strains results in resistance to or susceptibility to certain environment conditions

537 would be interesting to investigate in the future. More research will be required to determine if

538 this possible mycovirus toxin plays a role in common skin disorders caused by Malassezia by

539 targeting the host, bacteria, or fungi of the skin microbiome. 


\section{Materials and methods}

541 Strains

Malassezia sympodialis strains were stored at $-80^{\circ} \mathrm{C}$ in $25 \%$ glycerol stocks and

543 maintained on modified Dixon's (mDixon) medium at $30^{\circ} \mathrm{C}$. mDixon media is composed of $3.6 \%$

544 malt extract, $1 \%$ mycological peptone, $1 \%$ desiccated ox bile, $1 \%$ Tween $60,0.4 \%$ glycerol, and $5452 \%$ agar for solid medium.

\section{RNA extraction and dsRNA enrichment}

Total RNA was extracted from M. sympodialis liquid cultures as follows. $5 \mathrm{~mL}$ liquid mDixon cultures were grown at $30^{\circ} \mathrm{C}$ until saturation, approximately 3-4 days. Cultures were

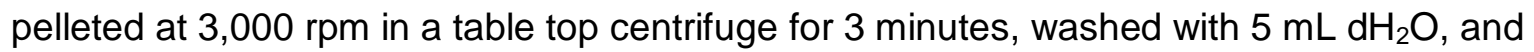
pellets were frozen at $-80^{\circ} \mathrm{C}$ until lyophilization overnight. Following lyophilization, pellets were broken up with $3 \mathrm{~mm}$ glass beads and the RNA extraction was performed using TRIzol (ThermoFisher, 15596026) according to the manufacturer's instructions. RNA was resuspended in $50 \mu$ l diethyl pyrocarbonate (DEPC) water. RNA was treated with TURBO DNase (ThermoFisher, \#AM2238) according to manufacturer's instructions, and resuspended in $50 \mu \mathrm{l}$ DEPC water. ssRNA precipitation/dsRNA enrichment was done overnight at $-20^{\circ} \mathrm{C}$ by combining $25 \mu \mathrm{l}$ of DNase treated RNA, with $28 \mu \mathrm{l} 8 \mathrm{M} \mathrm{LiCl}([$ final] $=2.8 \mathrm{M})$ and $27 \mu \mathrm{DEPC}$ water for a final volume of $80 \mu \mathrm{l}$. The mixture was centrifuged at $4^{\circ} \mathrm{C}$ for 10 minutes and the supernatant was recovered and transferred to a fresh eppendorf tube (the pellet can be saved and resuspended in $25 \mu \mathrm{L}$ DEPC water as a ssRNA control). To the supernatant, $7.5 \mu \mathrm{l} 3 \mathrm{M}$ $\mathrm{NaCl}([\mathrm{final}]=0.1 \mathrm{M})$ and $187.5 \mathrm{ul} 100 \%$ ethanol $([\mathrm{final}]=85 \%)$ was added and placed at $-20^{\circ} \mathrm{C}$ for at least 1 hour. dsRNA was pelleted at $4^{\circ} \mathrm{C}$ for 15 minutes and resuspended in $25 \mu \mathrm{LEPC}$ water. To visualize dsRNA and ssRNA bands, $10 \mu \mathrm{l}$ was electrophoresed on an $0.8 \%$ agarose gel stained with $5 \mu \mathrm{g} / \mathrm{mL}$ of ethidium bromide. 


\section{TA cloning of dsRNA segments}

Large and small dsRNA segments were purified from M. sympodialis strains KS012, KS013, KS016, and KS017 as described above. Large and small dsRNA segments were excised from the agarose gel and purified via gel extraction using the QIAquick Gel Extraction Kit (Qiagen, 28704) 3' adapter sequences from the Illumina TruSeq Small RNA Library Preparation Kit (Illumina, RS-200) were ligated onto the dsRNA species by mixing together $1 \mu$ l of adapter with $1 \mu \mathrm{g}$ dsRNA in a $6 \mu \mathrm{l}$ reaction and heated at $70^{\circ} \mathrm{C}$ for 2 minutes. Following heating, tubes were immediately placed on ice. To the adapter reaction, $2 \mu \mathrm{l}$ of HML ligation buffer, $1 \mu$ RNasin, and $1 \mu$ T T4 RNA Ligase 2 (truncated) was added and mixed by pipetting. The solution was incubated for 1 hour at $28^{\circ} \mathrm{C}$.

cDNA synthesis was achieved by combining $5 \mu$ of adapter-ligated dsRNA with $1 \mu$ l RT primer and heated at $70^{\circ} \mathrm{C}$ for 2 minutes, then immediately placed on ice. Next, the adapterligated/RT primer mixture was used as template with the AffinityScript cDNA Synthesis Kit (Agilent, 600559) with the following reaction conditions: $25^{\circ} \mathrm{C}$ for 5 minutes, $55^{\circ} \mathrm{C}$ for 15 minutes, $95^{\circ} \mathrm{C}$ for 5 minutes. cDNA was PCR amplified using the RT primer, cloned into the pCR-Blunt vector using the Zero Blunt PCR Cloning Kit (Invitrogen, K270020), and transformed into E. coli with One Shot TOP10 Chemically Competent E. coli (Invitrogen, C404003). Plasmids were extracted from purified bacterial colonies and subjected to Sanger sequencing (Genewiz) using universal M13F and M13R primers.

\section{RNA sequencing}

$5 \mathrm{~mL}$ liquid mDixon cultures were grown at $30^{\circ} \mathrm{C}$ for 3 days. Cells were pelleted at 3,000

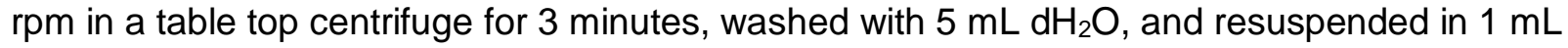
$\mathrm{dH}_{2} \mathrm{O}$. The $1 \mathrm{~mL}$ cell suspension was transferred to a bead beating tube with acid washed 425$600 \mu \mathrm{m}$ beads. Cells were pelleted with beads in a microcentrifuge at 6,000 rpm for 2 minutes. The supernatant was removed and the cell pellet was flash frozen in liquid nitrogen. Frozen 
bead/cell pellets were stored at $-80^{\circ} \mathrm{C}$ until RNA extraction. To prepare RNA, bead/cells pellets were thawed on ice and $1 \mathrm{~mL}$ TRIzol (ThermoFisher, 15596026) was added. Cells were bead beated 10 times in 1 minute 'on', 1 minute 'rest' cycles. Following bead beating, $200 \mu$ of chloroform was added and the RNA extraction continued as described in the manufacturer's

593 instructions. Final RNA pellets were treated with TURBO DNase (ThermoFisher, AM2238)

594 according to manufacturer's instructions, and RNA was resuspended in $50 \mu$ l of nuclease free

595 water (Promega, P119A). Illumina 150 bp PE libraries were prepared using the TruSeq

596 Stranded Total RNA-seq Kit in combination with the Illumina Ribozero Yeast Kit. Library preparation and RNA sequencing was performed at the Duke University Center for Genomic and Computation Biology.

After sequencing, Illumina raw reads were trimmed with Trimmomatic to remove Illumina adaptors (56). For the identification of the dsRNA mycovirus genome, one sequencing replicate of both the virus-infected and virus-cured strains was assembled into a transcriptome using 602 Trinity (57), which was run on Galaxy (58). The generated transcriptome was searched using 603 the TA-cloned sequences derived from both the large and small dsRNA segments. In silico 604 functional characterization of the mycovirus sequences was performed through blast analyses 605 and InterPro scan (https://www.ebi.ac.uk/interpro/search/sequence/). For RNA-seq analysis, the most recent $M$. sympodialis strain ATCC42132 genome assembly and annotation were used as a reference (30). Illumina reads from three independent biological replicates were trimmed with

608 Trimmomatic as reported above, and cleaned reads were mapped to the $M$. sympodialis 609 reference genome using HiSat. Generated .bam files were used to run StringTie with the $M$.

610 sympodialis annotation as guide, and the -e option to provide the correct output for the 611 statistical analysis (37). Read count information for statistical analysis were extracted using a 612 provided python script (prepDE.py). EdgeR was used to determine the differentially expressed 613 genes (DEGs) in the M. sympodialis virus-infected strain KS012 compared to its cured 614 counterpart SEC494. StringTie and EdgeR were run on Galaxy (58). DEGs were considered 
615 those with a FDR $<0.05$ and with a $\log _{2}$-fold change \pm 1 . Functional annotation of the DEGs was

616 performed using the Blast2GO pipeline, which includes the BLASTx against the NCBI non-

617 redundant protein database, gene ontology (GO) annotation and InterProScan (59). Heatmap

618 for the DEGs was generated using the web-based server heatmapper with the average linkage

619 for hierarchical clustering (http://www.heatmapper.ca/expression/), and gene network interaction

620 were determined using STRING (https://string-db.org/cgi/input.pl) with the $S$. cerevisiae protein

621 set as reference.

622 Whole genome DNA sequencing and assembly

$62325 \mathrm{~mL}$ liquid mDixon cultures of M. sympodialis KS012 and SEC494 were grown at $30^{\circ} \mathrm{C}$

624 for 3 days. Cells were pelleted at 3,000 rpm in a table top centrifuge for 3 minutes, washed with

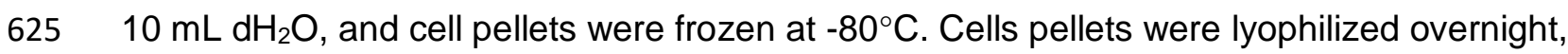

626 pulverized using $3 \mathrm{~mm}$ glass beads, and subjected to genomic DNA extraction using the CTAB

627 method (60). Library preparation and 50 bp PE Illumina sequencing was performed at the Duke

628 University Center for Genomic and Computation Biology. Illumina reads for M. sympodialis

629 KS012 and SEC494 were assembled using SPAdes with default parameters (61). Dot plot

630 comparisons were carried out using nucmer with the -nosymplify, --filter, and -fat parameters;

631 nucmer was run on Galaxy. The de novo genome assembly of M. sympodialis KS012 was used

632 for blast searches using both large and small dsRNA viral sequences.

SEC494 were mapped to the M. sympodialis reference ATCC42132 using BWA (62), and the

635 resulting .sam file converted to .bam with samtools (63). Bam files were converted in .tdf format

636 using IGV, and the read coverage for M. sympodialis virus-infected strain KS012 and virus-

637 cured SEC494 visualized in the IGV browser using the M. sympodialis ATCC42132 as

638 reference. For variant analysis, the .bam files were generated as above and the M. sympodialis

639 reference ATCC42132 genome were used to run samtools mpileup; variant analysis was carried 
640

641

642

out using the bcftools call option; the resulting .vcf file was merged with the M. sympodialis annotation using the variant effector predictor software present on the EnsembIFungi database (https://fungi.ensembl.org/Malassezia_sympodialis_atcc_42132_gca_900149145/Info/Index).

\section{Phylogenetic analysis}

The MsMV1 Rdp1 was aligned with representative viral Rdp1 sequences found on NCBI using the Mega7 software. Phylogenies were built using 100 bootstrap values using the Maximum Likelihood method based on the Tamura-Nei model (64). Protein domains were predicted using NCBI Blastp and images were created using the MyDomain Image Creator from PROSITE on the ExPASy Bioinformatics resource portal.

\section{Murine topical infection model}

WT C57BL/6j mice were purchased by Janvier Elevage and maintained at the Laboratory Animal Science Center of University of Zurich, Zurich, Switzerland. Mice were used at 6-12 weeks in sex-and age-matched groups. Epicutaneous infection of the mouse ear skin was performed as described $(41,65)$. Briefly, Malassezia strains were grown for 3-4 days at $30^{\circ} \mathrm{C}, 180 \mathrm{rpm}$ in liquid mDixon medium. Cells were washed in PBS and suspended in native olive oil at a density of $20 \mathrm{OD}_{\mathrm{A} 600} / \mathrm{mL} .100 \mu \mathrm{l}$ suspension (corresponding to $2 \mathrm{OD}_{\mathrm{A} 600}$ ) of yeast cells was applied topically onto the dorsal ear skin that was previously disrupted by mild tape stripping while mice were anaesthetized. Ear thickness was monitored prior and after infection using an Oditest S0247 0-5 mm measurement device (KROEPLIN) and the increase was calculated by subtracting the values measured prior to the experiments from those measured at the endpoint. For each animal, the mean of the ear thickness from both ears was calculated. For determining the fungal loads in the skin, tissue was transferred in water supplemented with 0.05\% Nonidet P40 (AxonLab), homogenized and plated on modified Dixon agar and incubated at $30^{\circ} \mathrm{C}$ for $3-4$ days. 


\section{Macrophage infection in vitro}

Macrophages were generated from WT C57BI/6j, TIr3-- (66) (Swiss Immunological Mouse Repository (SwImMR) hosted by the University of Zurich) bone marrow cells in the presence of $20 \%$ L929 conditioned R10* medium. After 6 days of culture, cells were detached using PBS/5\% FCS/2.5 mM EDTA and seeded at a density of $10^{5}$ cells/100 $\mu$ in 96 -well tissue culture plates (for transcript analysis) and $10^{6}$ cells $/ 1 \mathrm{~mL}$ in 24-well plates (for FACS analysis). Cells were rested overnight and infected the next day with Malassezia at the indicated MOI for 16 hours (for FACS analysis) or for 24 hours (for transcript analysis). Polyl:C $(50 \mu \mathrm{g} / \mathrm{mL})$ was included as a control.

\section{Flow cytometry}

Macrophages were gently detached by using cell scrapers and stained with antibodies directed against CD11b (clone M1/70), F4/80 (clone BM8), CD86 (clone GL-1), and MHC-II (clone M5/114.15.2) in PBS supplemented with 1\% FCS, 5 mM EDTA and $0.02 \% \mathrm{NaN}_{3}$.

LIVE/DEAD Near IR stain (Life Technologies) was used for exclusion of dead cells. Cells were acquired on a FACS Cytoflex (Beckman Coulter) and the data were analyzed with FlowJo software (FlowJo LLC). The gating of the flow cytometric data was performed according to the guidelines for the use of flow cytometry and cell sorting in immunological studies (67), including pre-gating on viable and single cells for analysis.

\section{RNA extraction and quantitative RT-PCR}

Isolation of total RNA from ear skin and from BMDM cultures was carried out according to standard protocols using TRI Reagent (Sigma Aldrich). cDNA was generated by RevertAid reverse transcriptase (ThermoFisher). Quantitative PCR was performed using SYBR Green (Roche) and a QuantStudio 7 Flex (Life Technologies) instrument. The primers used for qPCR were as follows: I/17a forward 5'-GCTCCAGAAGGCCCTCAGA-3', reverse 5'AGCTTTCCCTCCGCATTGA-3' (68); Tnf forward 5'-CATCTTCTCAAAATTCGAGTGACAA-3', 
reverse 5'-TGGGAGTAGACAAGGTACAACCC-3' (69); Ifnb forward 5'-

AACCTCACCTACAGGGC-3', reverse 5'-CATTCTGGAGCATCTCTTGG-3' (43); Actb forward

692 qPCR assays were performed in duplicate and the relative expression (rel. expr.) of each gene 693 was determined after normalization to Actb transcript levels.

694 Data availability

695 Both sequencing reads for M. sympodialis virus-infected strain KS012 and M. sympodialis virus696 cured strain SEC494 are available in the NCBI SRA database (BioProject PRJNA593722). The

697 large and small dsRNA fragments of the mycovirus genome have been deposited in GenBank 698 under accession numbers MN812428 and MN831678, respectively.

\section{Acknowledgements}

We thank Marco A. Coelho for performing the genomic assemblies of the virus-infected

701 and virus-cured M. sympodialis KS012 and SEC494 strains. This work was supported by

702 NIH/NIAID R37 award AI39115-22 and R01 award AI50113-15 awarded to JH and by SNSF grant 310030_189255 awarded to SLL. JH is a Co-Director and Fellow of the CIFAR program

704 Fungal Kingdom: Threats \& Opportunities. We thank Blake Billmyre and other members of the

705 Heitman lab, as well as Florian Sparber, Amanda McLeod, and Jessica Shannon for helpful 706 discussions and comments on the manuscript. 


\section{References}

1. Bevan EA, Herring AJ, Mitchell DJ. 1973. Preliminary characterization of two species of dsRNA in yeast and their relationship to the "killer" character. Nature 245:81-86.

2. Park C-M, Banerjee N, Koltin Y, Bruenn JA. 1996. The Ustilago maydis virally encoded KP1 killer toxin. Molecular Microbiology 20:957-963.

3. Wu M, Jin F, Zhang J, Yang L, Jiang D, Li G. 2012. Characterization of a novel bipartite double-stranded RNA mycovirus conferring hypovirulence in the phytopathogenic fungus Botrytis porri. Journal of Virology 86:6605-6619.

4. Lau SKP, Lo GCS, Chow FWN, Fan RYY, Cai JJ, Yuen K-Y, Woo PCY. 2018. Novel partitivirus enhances virulence of and causes aberrant gene expression in Talaromyces marneffei. mBio 9:e00947-18.

5. Son M, Yu J, Kim K-H. 2015. Five questions about mycoviruses. PLoS Pathogens 11:e1005172.

6. Ghabrial SA, Castón JR, Jiang D, Nibert ML, Suzuki N. 2015. 50-plus years of fungal viruses. Virology 479-480:356-368.

7. King AMQ, Adams MJ, Carstens EB, Lefkowitz EJ. 2012. Part II. The Viruses, p 21-36, Virus Taxonomy doi:https://doi.org/10.1016/B978-0-12-384684-6.00115-4. Elsevier, San Diego.

8. Ghabrial SA, Suzuki N. 2009. Viruses of plant pathogenic fungi. Annual Review of Phytopathology 47:353-384.

9. Fink GR, Styles CA. 1972. Curing of a killer factor in Saccharomyces cerevisiae. PNAS 69:2846-49.

10. Bevan EA, Somers JM. 2009. Somatic segregation of the killer (k) and neutral (n) cytoplasmic genetic determinants in yeast. Genetical Research 14:71-77.

11. Herring AJ, Bevan EA. 1974. Virus-like particles associated with the double-stranded RNA species found in killer and sensitive strains of the yeast Saccharomyces cerevisiae. Journal of General Virology 22:387-394.

12. Bostian KA, Elliott Q, Bussey H, Bum V, Smith AI, Tipper DJ. 1984. Sequence of the preprotoxin dsRNA gene of type I killer yeast: multiple processing events produce a twocomponent toxin. Cell 36:741-751.

13. Schmitt MJ, Breinig F. 2006. Yeast viral killer toxins: lethality and self-protection. Nature Reviews Microbiology 4:212-221.

14. Wickner RB. 1996. Double-stranded RNA viruses of Saccharomyces cerevisiae. Microbiological reviews 60:250-265.

15. Somers JM, Bevan EA. 2009. The inheritance of the killer character in yeast. Genetical Research 13:71-83.

16. Chen B, Nuss DL. 1999. Infectious cDNA clone of hypovirus CHV1-Euro7: a comparative virology approach to investigate virus-mediated hypovirulence of the chestnut blight fungus Cryphonectria parasitica. Journal of Virology 73:985-992.

17. Rigling D, Prospero S. 2018. Cryphonectria parasitica, the causal agent of chestnut blight: invasion history, population biology and disease control. Molecular Plant Pathology 19:7-20.

18. Hillman BI, Suzuki N. 2004. Viruses of the chestnut blight fungus, Cryphonectria parasitica, p 423-472, Advances in Virus Research, vol 63. Academic Press.

19. Thapa V, Turner GG, Hafenstein S, Overton BE, Vanderwolf KJ, Roossinck MJ. 2016. Using a novel partitivirus in Pseudogymnoascus destructans to understand the epidemiology of white-nose syndrome. PLoS Pathogens 12:e1006076.

20. Drinnenberg IA, Fink GR, Bartel DP. 2011. Compatibility with killer explains the rise of RNAi-deficient fungi. Science 333:1592-1592. 
792

793

794

795

796

797

798

799

800

801

802

803

804

805

806

21. Segers GC, Zhang X, Deng F, Sun Q, Nuss DL. 2007. Evidence that RNA silencing functions as an antiviral defense mechanism in fungi. PNAS 104:12902-12906.

22. Deleris A, Gallego-Bartolome J, Bao J, Kasschau KD, Carrington JC, Voinnet O. 2006. Hierarchical action and inhibition of plant dicer-like proteins in antiviral defense. Science 313:68-71.

23. Hammond TM, Andrewski MD, Roossinck MJ, Keller NP. 2008. Aspergillus mycoviruses are targets and suppressors of RNA silencing. Eukaryotic Cell 7:350-357.

24. Segers GC, van Wezel R, Zhang X, Hong Y, Nuss DL. 2006. Hypovirus papain-like protease p29 suppresses RNA silencing in the natural fungal host and in a heterologous plant system. Eukaryotic Cell 5:896-904.

25. Yaegashi H, Yoshikawa N, Ito T, Kanematsu S. 2013. A mycoreovirus suppresses RNA silencing in the white root rot fungus, Rosellinia necatrix. Virology 444:409-416.

26. Gaitanis G, Magiatis P, Hantschke M, Bassukas ID, Velegraki A. 2012. The Malassezia genus in skin and systemic diseases. Clinical Microbiology Reviews 25:106-141.

27. Limon JJ, Tang J, Li D, Wolf AJ, Michelsen KS, Funari V, Gargus M, Nguyen C, Sharma P, Maymi VI, Iliev ID, Skalski JH, Brown J, Landers C, Borneman J, Braun J, Targan SR, McGovern DPB, Underhill DM. 2019. Malassezia is associated with Crohn's disease and exacerbates colitis in mouse models. Cell Host \& Microbe 25:377-388.

28. Aykut B, Pushalkar S, Chen R, Li Q, Abengozar R, Kim JI, Shadaloey SA, Wu D, Preiss P, Verma N, Guo Y, Saxena A, Vardhan M, Diskin B, Wang W, Leinwand J, Kurz E, Kochen Rossi JA, Hundeyin M, Zambrinis C, Li X, Saxena D, Miller G. 2019. The fungal mycobiome promotes pancreatic oncogenesis via activation of MBL. Nature 574:264267.

29. Wu G, Zhao H, Li C, Rajapakse MP, Wong WC, Xu J, Saunders CW, Reeder NL, Reilman RA, Scheynius A, Sun S, Billmyre BR, Li W, Averette AF, Mieczkowski P, Heitman J, Theelen B, Schröder MS, De Sessions PF, Butler G, Maurer-Stroh S, Boekhout T, Nagarajan N, Dawson TL, Jr. 2015. Genus-wide comparative genomics of Malassezia delineates its phylogeny, physiology, and niche adaptation on human skin. PLoS Genetics $11: e 1005614$.

30. Zhu Y, Engström PG, Tellgren-Roth C, Baudo CD, Kennell JC, Sun S, Billmyre RB, Schröder MS, Andersson A, Holm T, Sigurgeirsson B, Wu G, Sankaranarayanan SR, Siddharthan R, Sanyal K, Lundeberg J, Nystedt B, Boekhout T, Dawson TL, Jr., Heitman J, Scheynius A, Lehtiö J. 2017. Proteogenomics produces comprehensive and highly accurate protein-coding gene annotation in a complete genome assembly of Malassezia sympodialis. Nucleic Acids Research 45:2629-2643.

31. Glatz M, Bosshard PP, Hoetzenecker W, Schmid-Grendelmeier P. 2015. The role of Malassezia spp. in atopic dermatitis. Journal of Clinical Medicine 4:1217-1228.

32. Fink GR, Styles CA. 1972. Curing of a killer factor in Saccharomyces cerevisiae. Proceedings of the National Academy of Sciences 69:2846.

33. Kotta-Loizou I, Coutts RHA. 2017. Mycoviruses in Aspergilli: a comprehensive review. Frontiers In Microbiology 8:1699-1699.

34. Dinman JD, Icho T, Wickner RB. 1991. A -1 ribosomal frameshift in a double-stranded RNA virus of yeast forms a gag-pol fusion protein. PNAS 88:174-178.

35. Taylor DJ, Ballinger MJ, Bowman SM, Bruenn JA. 2013. Virus-host co-evolution under a modified nuclear genetic code. PeerJ 1:e50.

36. Käll L, Krogh A, Sonnhammer ELL. 2004. A combined transmembrane topology and signal peptide prediction method. Journal of Molecular Biology 338:1027-1036.

37. Pertea M, Kim D, Pertea GM, Leek JT, Salzberg SL. 2016. Transcript-level expression analysis of RNA-seq experiments with HISAT, StringTie, and Ballgown. Nature Protocols $11: 1650-1667$. 
807

808

809

810

811

812

813

814

815

816

817

818

819

820

821

822

823

824

825

826

827

828

829

830

831

832

833

834

835

836

837

838

839

840

841

842

843

844

845

846

847

848

849

850

851

852

853

854

855

856

38. Robinson MD, McCarthy DJ, Smyth GK. 2010. edgeR: a Bioconductor package for differential expression analysis of digital gene expression data. Bioinformatics 26:139140.

39. Allen BL, Taatjes DJ. 2015. The Mediator complex: a central integrator of transcription. Nature Reviews 16:155-166.

40. Janz A, Oezel M, Kurzeder C, Mautner J, Pich D, Kost M, Hammerschmidt W, Delecluse HJ. 2000. Infectious Epstein-Barr virus lacking major glycoprotein BLLF1 (gp350/220) demonstrates the existence of additional viral ligands. Journal of Virology 74:1014210152.

41. Sparber F, De Gregorio C, Steckholzer S, Ferreira FM, Dolowschiak T, Ruchti F, Kirchner FR, Mertens S, Prinz I, Joller N, Buch T, Glatz M, Sallusto F, LeibundGutLandmann S. 2019. The skin commensal yeast Malassezia triggers a type 17 response that coordinates anti-fungal immunity and exacerbates skin inflammation. Cell Host \& Microbe 25:389-403.

42. Weischenfeldt J, Porse B. 2008. Bone marrow-derived macrophages (BMM): isolation and applications. Cold Spring Harbor Protocols 2008.

43. Ives A, Ronet C, Prevel F, Ruzzante G, Fuertes-Marraco S, Schutz F, Zangger H, Revaz-Breton M, Lye L-F, Hickerson SM, Beverley SM, Acha-Orbea H, Launois P, Fasel N, Masina S. 2011. Leishmania RNA virus controls the severity of mucocutaneous leishmaniasis. Science 331:775-778.

44. de Carvalho RVH, Lima-Junior DS, da Silva MVG, Dilucca M, Rodrigues TS, Horta CV, Silva ALN, da Silva PF, Frantz FG, Lorenzon LB, Souza MM, Almeida F, Cantanhêde LM, Ferreira RdGM, Cruz AK, Zamboni DS. 2019. Leishmania RNA virus exacerbates Leishmaniasis by subverting innate immunity via TLR3-mediated NLRP3 inflammasome inhibition. Nature Communications 10:5273.

45. Alexopoulou L, Holt AC, Medzhitov R, Flavell RA. 2001. Recognition of double-stranded RNA and activation of NF-kB by Toll-like receptor 3. Nature 413:732-738.

46. Parsell DA, Lindquist S. 1993. The function of heat-shock proteins in stress tolerance: degradation and reactivation of damaged proteins. Annual Review of Genetics 27:437496.

47. Lee Marzano S-Y, Neupane A, Domier L. 2018. Transcriptional and small RNA responses of the white mold fungus Sclerotinia sclerotiorum to infection by a virulenceattenuating hypovirus. Viruses 10:713.

48. Lukša J, Ravoitytè B, Konovalovas A, Aitmanaitè L, Butenko A, Yurchenko V, Serva S, Servienè E. 2017. Different metabolic pathways are involved in response of Saccharomyces cerevisiae to L-A and M viruses. Toxins 9:233.

49. Baidya S, Cary JW, Grayburn WS, Calvo AM. 2011. Role of nitric oxide and flavohemoglobin homolog genes in Aspergillus nidulans sexual development and mycotoxin production. Applied and Environmental Microbiology 77:5524-5528.

50. Ianiri G, Coelho M, Ruchti F, Sparber F, McMahon T, Fu C, Bolejack M, Donovan O, Smutney H, Myler P, Dietrich F, Fox III D, LeibundGut-Landmann S, Heitman J. 2020. Horizontal gene transfer in the human and skin commensal Malassezia: a bacteriallyderived flavohemoglobin is required for $\mathrm{NO}$ resistance and host interaction. bioRxiv 2020.01.28.923367.

51. Zhang X, Segers GC, Sun Q, Deng F, Nuss DL. 2008. Characterization of hypovirusderived small RNAs generated in the chestnut blight fungus by an inducible DCL-2dependent pathway. Journal of Virology 82:2613-2619.

52. Sun Q, Choi GH, Nuss DL. 2009. A single Argonaute gene is required for induction of RNA silencing antiviral defense and promotes viral RNA recombination. PNAS 106:17927-17932. 
857

858

859

860

861

862

863

864

865

866

867

868

869

870

871

872

873

874

875

876

877

878

879

880

881

882

883

884

885

886

887

888

889

890

891

892

893

894

895

896

897

898

899

900

901

902

903

904

905

906

907

53. Davis ES, Becker A, Heitman J, Hall MN, Brennan MB. 1992. A yeast cyclophilin gene essential for lactate metabolism at high temperature. PNAS 89:11169-11173.

54. Ma H, Hagen F, Stekel DJ, Johnston SA, Sionov E, Falk R, Polacheck I, Boekhout T, May RC. 2009. The fatal fungal outbreak on Vancouver Island is characterized by enhanced intracellular parasitism driven by mitochondrial regulation. PNAS 106:1298012985.

55. Bekisz J, Sato Y, Johnson C, Husain SR, Puri RK, Zoon KC. 2013. Immunomodulatory effects of interferons in malignancies. Journal of Interferon \& Cytokine Research 33:154161.

56. Bolger AM, Lohse M, Usadel B. 2014. Trimmomatic: a flexible trimmer for Illumina sequence data. Bioinformatics 30:2114-2120.

57. Haas BJ, Papanicolaou A, Yassour M, Grabherr M, Blood PD, Bowden J, Couger MB, Eccles D, Li B, Lieber M, MacManes MD, Ott M, Orvis J, Pochet N, Strozzi F, Weeks N, Westerman R, William T, Dewey CN, Henschel R, LeDuc RD, Friedman N, Regev A. 2013. De novo transcript sequence reconstruction from RNA-seq using the Trinity platform for reference generation and analysis. Nature Protocols 8:1494-1512.

58. Afgan E, Baker D, Batut B, van den Beek M, Bouvier D, Cech M, Chilton J, Clements D, Coraor N, Grüning BA, Guerler A, Hillman-Jackson J, Hiltemann S, Jalili V, Rasche H, Soranzo N, Goecks J, Taylor J, Nekrutenko A, Blankenberg D. 2018. The Galaxy platform for accessible, reproducible, and collaborative biomedical analyses: 2018 update. Nucleic Acids Research 46:W537-W544.

59. Conesa A, Götz S, García-Gómez JM, Terol J, Talón M, Robles M. 2005. Blast2GO: a universal tool for annotation, visualization, and analysis in functional genomics research. Bioinformatics 21:3674-3676.

60. Pitkin JW, Panaccione DG, Walton JD. 1996. A putative cyclic peptide efflux pump encoded by the TOXA gene of the plant-pathogenic fungus Cochliobolus carbonum. Microbiology 142:1557-1565.

61. Bankevich A, Nurk S, Antipov D, Gurevich AA, Dvorkin M, Kulikov AS, Lesin VM, Nikolenko SI, Pham S, Prjibelski AD, Pyshkin AV, Sirotkin AV, Vyahhi N, Tesler G, Alekseyev MA, Pevzner PA. 2012. SPAdes: a new genome assembly algorithm and its applications to single-cell sequencing. Journal of Computational Biology 19:455-477.

62. Li H, Durbin R. 2010. Fast and accurate long-read alignment with Burrows-Wheeler transform. Bioinformatics 26:589-595.

63. Li H, Handsaker B, Wysoker A, Fennell T, Ruan J, Homer N, Marth G, Abecasis G, Durbin R, Genome Project Data Processing S. 2009. The sequence alignment/map format and SAMtools. Bioinformatics 25:2078-2079.

64. Tamura K, Nei M. 1993. Estimation of the number of nucleotide substitutions in the control region of mitochondrial DNA in humans and chimpanzees. Molecular Biology and Evolution 10:512-526.

65. Sparber F, LeibundGut-Landmann S. 2019. Infecting mice with Malassezia spp. to study the fungus-host interaction. Journal of Visualized Experiments doi:doi:10.3791/60175:e60175.

66. Honda K, Sakaguchi S, Nakajima C, Watanabe A, Yanai H, Matsumoto M, Ohteki T, Kaisho T, Takaoka A, Akira S, Seya T, Taniguchi T. 2003. Selective contribution of IFNalpha/beta signaling to the maturation of dendritic cells induced by double-stranded RNA or viral infection. PNAS 100:10872-10877.

67. Cossarizza A, al e. 2019. Guidelines for the use of flow cytometry and cell sorting in immunological studies (second edition). European Journal of Immunology 49:1457-1973.

68. Overbergh L, Giulietti A, Valckx D, Decallonne R, Bouillon R, Mathieu C. 2003. The use of real-time reverse transcriptase PCR for the quantification of cytokine gene expression. Journal of Biomolecular Techniques 14:33-43. 
bioRxiv preprint doi: https://doi.org/10.1101/2019.12.18.880518; this version posted June 11, 2020. The copyright holder for this preprint (which was not certified by peer review) is the author/funder, who has granted bioRxiv a license to display the preprint in perpetuity. It is made available under aCC-BY-NC-ND 4.0 International license.

908

909

910

911

912

913

69. Schönherr FA, Sparber F, Kirchner FR, Guiducci E, Trautwein-Weidner K, Gladiator A, Sertour N, Hetzel U, Le GTT, Pavelka N, d'Enfert C, Bougnoux ME, Corti CF, LeibundGut-Landmann S. 2017. The intraspecies diversity of $C$. albicans triggers qualitatively and temporally distinct host responses that determine the balance between commensalism and pathogenicity. Mucosal Immunology 10:1335-1350. 


\section{$914 \quad$ Figure legends}

915 Figure 1. Malassezia species harbor dsRNA segments. A) dsRNA from representative $M$.

916 sympodialis strains. B) dsRNA from additional Malassezia species. Strain names can be found

917 in Table 1. C) dsRNA (upper panel) and ssRNA (lower panel) from M. sympodialis strains

918 passaged at $30^{\circ} \mathrm{C}, 37^{\circ} \mathrm{C}$, and on mDixon media containing $10 \mu \mathrm{g} / \mathrm{mL}$ biphenyl. All dsRNA and

919 ssRNA extracts were visualized by electrophoresis in $0.8 \%$ agarose gels with $0.5 \mu \mathrm{g} / \mathrm{mL}$

920 ethidium bromide.

921

922

923

924

925

926

927

928

929

930

931

932

933

934

935

936

937

938 Green represents upregulated genes and red represents downregulated genes. D) Gene

Figure 2. dsRNA segments code for viral protein products. A) Representative region of the large dsRNA segment illustrating the two open reading frames for the capsid and Rdp1 and the site of the -1 ribosomal frameshift. Stop codon for capsid highlighted in red. Start codon for Rdp1 highlighted in green. Frameshift site highlighted in blue. B) Phylogenetic analysis of mycovirus Rdp1 sequences. Scale bar represents the number of substitutions per site. Blue boxes on protein diagrams represent the reverse transcriptase $(\mathrm{RT})$ domain of the Rdp1 protein. C) Protein sequence of the small dsRNA segment. The signal peptide is underlined and hydrophobic residues indicated with stars. D) Pictorial representation of predicted domains of the small dsRNA segment.

Figure 3. RNA-seq reveals transcriptional rewiring in virus-infected M. sympodialis strain. A) Dot plot of $\log _{2}$ fold-changes in gene expression in the virus-infected strain KS012. Red and blue dots represent upregulated and downregulated genes that pass a false discovery rate (FDR) of $5 \%$, respectively. Gray dots indicate genes that do not meet the FDR. The virus-cured strain SEC494 was used as the baseline for gene expression, and a gene is marked as differentially expressed in the virus-infected strain KS012 if expression differs from SEC494. B) Number of genes upregulated (red) and downregulated (blue) categorized by gene ontology. C) Heat map of the three RNA-seq technical replicates of virus-infected and virus-cured strains. 
Supplemental Figure 3. Select virus-infected strains exhibit increased ability to colonize skin in

network map of upregulated genes in virus-infected strain. Genes are clustered by color based on the Markov-Cluster (MCL) inflation parameter.

Figure 4. MsMV1 dsRNA virus induces interferon- $\beta$ (IFN- $\beta$ ) expression in cultured macrophages in a TLR3-independent manner. A) IFN- $\beta$ expression in bone marrow-derived macrophages (BMDM) after infection with the indicated virus-infected and virus-cured strains at $\mathrm{MOI}=5$ for 24 hours. Bars are the mean + SEM of four replicate samples with each being the pool of two separate wells. Data are pooled from two independent experiments. B) IFN- $\beta$ expression by wildtype (solid bars) and TIr3-/- (dashed bars) BMDM after infection with the indicated virus-infected and virus-cured strains at $\mathrm{MOI}=5$ for $24 \mathrm{~h}$. Bars are a pool of two wells. Data are representative of one out of two independent experiments. polyl:C (pl:C) was included as a positive control; US, unstimulated. The dotted line indicates the expression levels under unstimulated conditions. Statistics were calculated using unpaired Student's t test. ${ }^{*} p<0.05$, ${ }^{* *} p<0.01$. Black bars below the $x$-axis labels group virus-infected/virus-cured strain pairs. ' + ' indicates virus-infected, '-' indicates virus-cured.

Supplemental Figure 1. Malassezia species harbor dsRNA segments. dsRNA from select $M$. sympodialis (A) and M. furfur (B) strains was analyzed by electrophoresis on a $0.8 \%$ agarose gel with $0.5 \mu \mathrm{g} / \mathrm{mL}$ ethidium bromide.

Supplemental Figure 2. Genomic comparisons of $M$. sympodialis virus-infected and viruscured strains compared to the reference strain ATCC42132. (A-C) Dot plot comparison of the $M$. sympodialis strain ATCC42132 with the virus-infected M. sympodialis KS012 (A) and the viruscured SEC494 (B), and of KS012 and SEC494. (C) Read coverage of the M. sympodialis strains KS012 and virus-cured SEC494 compared to the haploid reference strain ATCC42132
a murine ear skin infection model. A) Fungal load, B) ear thickening, and C) cytokine expression 
963 in the skin of mice that were epicutaneously infected with the indicated virus-infected and virus-

964 cured strain pairs for 4 days, D) 2 days, or E) 7 days. The mean + SEM of each group is

965 indicated. Data in A-C are pooled from two independent experiments with $n=6$ mice for all

966 groups, except n=3 for KS015 and SEC497. DL, detection limit. Statistics were calculated using

967 One-way ANOVA. * $p<0.05,{ }^{* * *} p<0.0001$. Black bars below the $x$-axis labels group virus-

968 infected/virus-cured strain pairs. '+' indicates virus-infected, '-‘ indicates virus-cured.

969 Supplemental Figure 4. Macrophage viability, CD86 expression, and TNF expression is not

970 affected by the presence of MsMV1 in M. sympodialis strains. A) BMDM were infected with the

971 indicated virus-infected and virus-cured strains at $\mathrm{MOI}=1$ and analyzed for viability and CD86

972 surface expression by flow cytometry at 16 hours post-infection or infected at $\mathrm{MOI}=5$ and

973 analyzed for TNF expression by RT-qPCR at 24 hours post-infection. Each bar represents the

974 mean + SEM of four samples, each being the pool of two separate wells. Data are pooled from

975 two independent experiments. The dotted line indicates the expression levels under

976 unstimulated conditions. B) Flow cytometry gating strategy used to assess BMDM viability (top

977 row) and CD86 expression (bottom row). C) BMDM viability, CD86 surface expression and TNF

978

979

980

981

982

983

984

985

986

987 expression of wild-type and T/r3-/- BMDM infected with the indicated virus-infected and virus-

cured strains and analyzed as in A). Data are from one out of two representative experiment

with each value being the pool of two wells. Statistics were calculated using an unpaired

Student's t test. *p<0.05. '+' superscripts indicate virus-infected strains, '-' superscripts indicate virus-cured.

Table 1. Strains used in dsRNA gel images. Strains are listed top to bottom in order of gel wells from left to right. If known, clinical data and sample location are listed. $U=$ unknown, $H=$ healthy individual, $\mathrm{D}=$ dandruff, $\mathrm{TV}=$ tinea versicolor, $\mathrm{PV}=$ pityriasis versicolor, $\mathrm{SD}=$ seborrheic dermatitis, OE = otitis externa. “*' indicates strains sampled from an animal.

Table 2. Strains used in this study. 
Table S1. Variants present only in the M. sympodialis virus-cured SEC494 compared to the virus-infected KS012.

File S1. Identification of the large dsRNA segment of the M. sympodialis MsMV1. Note that the designations “TRINITY_DN8321_c1_g1_i1 len=4613 path=[4591:0-4612] [-1, 4591, -2]" and “TRINITY_DN4986_c1_g1_i1 len=4601 path=[4579:0-4600] [-1, 4579, -2]" are automatically

993 generated by the software Trinity. We arbitrary used the denomination DN8321 and DN4986 to 994 indicate the contigs that represent the M. sympodialis MsMV1 mycovirus genome, as identified 995 by blast analyses. Considering "TRINITY_DN8321_c1_g1_i1 len=4613 path=[4591:0-4612] [-1, 996 4591, -2]", according to the software instructions, TRINITY_DN8321_c1_g1_i1 indicates Trinity 997 read cluster 'TRINITY_DN8321_c1', gene ' $g 1$ ', and isoform 'i1'. 'Len' indicates the length of the 998 cluster (contig) in bp, and path information indicates the path traversed in the Trinity compacted 999 de Bruijn graph to construct that transcript.

1000 File S2. Identification of the small dsRNA segment of the M. sympodialis MsMV1. For the 1001 contigs designation, see explanation in the legend of File S1.

1002 File S3. Screenshot of the variants presents in the coding regions of the genes $K A E 1$ and 1003 CRM1 in the M. sympodialis strains SEC494.

1004

1005

1006

1007

1008

1009

1010

1011 
Figure 1

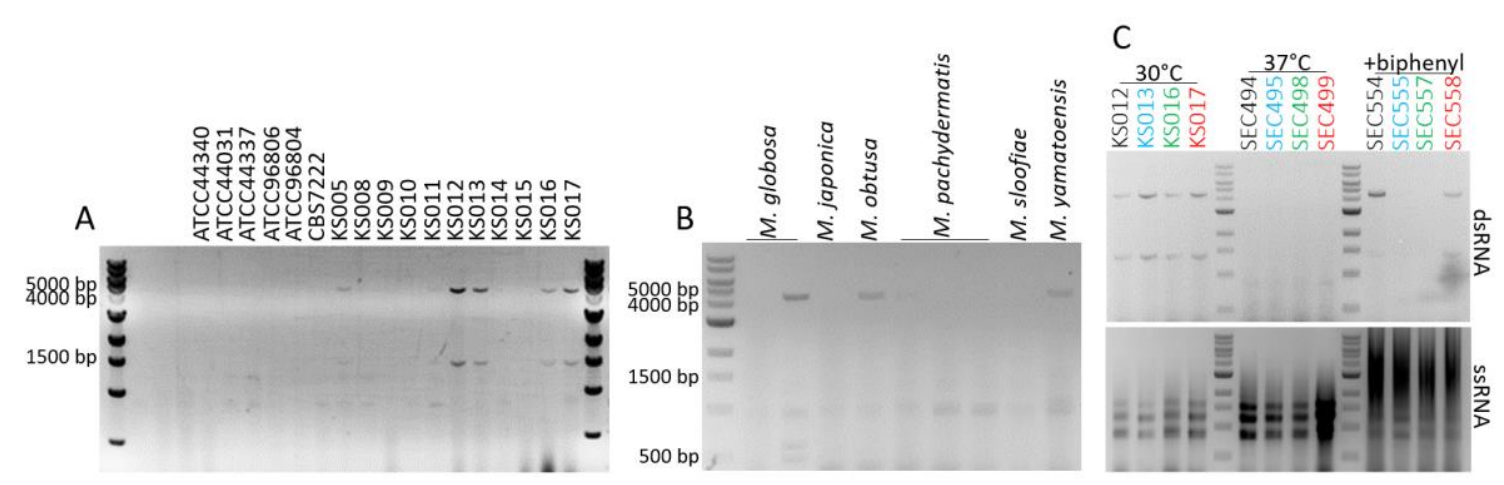


bioRxiv preprint doi: https://doi.org/10.1101/2019.12.18.880518; this version posted June 11, 2020. The copyright holder for this preprint (which was not certified by peer review) is the author/funder, who has granted bioRxiv a license to display the preprint in perpetuity. It is made available under aCC-BY-NC-ND 4.0 International license.

1032

A ...TCTGCATtGAAGTATAGATTCCAGGGTITACACTGGCTGCG

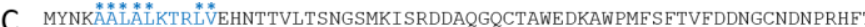
NCLFFVYISVCCGVHYGDDFDGSEWNCNDVSAI PNPFNSIOTSGGMMGTQAYLLVDHTCPPSEKGEG DKLATFDPGDGRCIPVKFEGGNGYTVKNVGENKIDGNTQWIDTDANNGRYKLGKRSENCKAFKWDNK PAEGTNTPSVDVPNSFTDCTGSSDDCKINVDEEQSVTVGMTVSVSVGSDFIVSVNTEVGTSYEESRS AGTCAAGAAAATGCACCCGTTGTCCATTTACAATCATCGCATAT GGACACGGCCGACTTGCAGCCAGTCGAGGACTTTCAAGATCC Frame 2, Capsid
GGCTGGTGCTCCGGAGGAGCCTGAATCTAACTACCATGATT TGAGTAGTTATCATAACCCGITGCCCTTGTACCTTGACGAAAAG TATGATAACTCGTTGCCTGAGAAGTGTTCGTATATTCTTATGTAT B Frame 1, RDP1
GTATCCAACGATGATGTGCCTTCACATGTTGTTATTACCCATT...

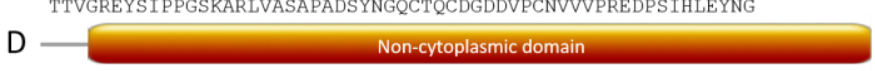

$\mathrm{D}$
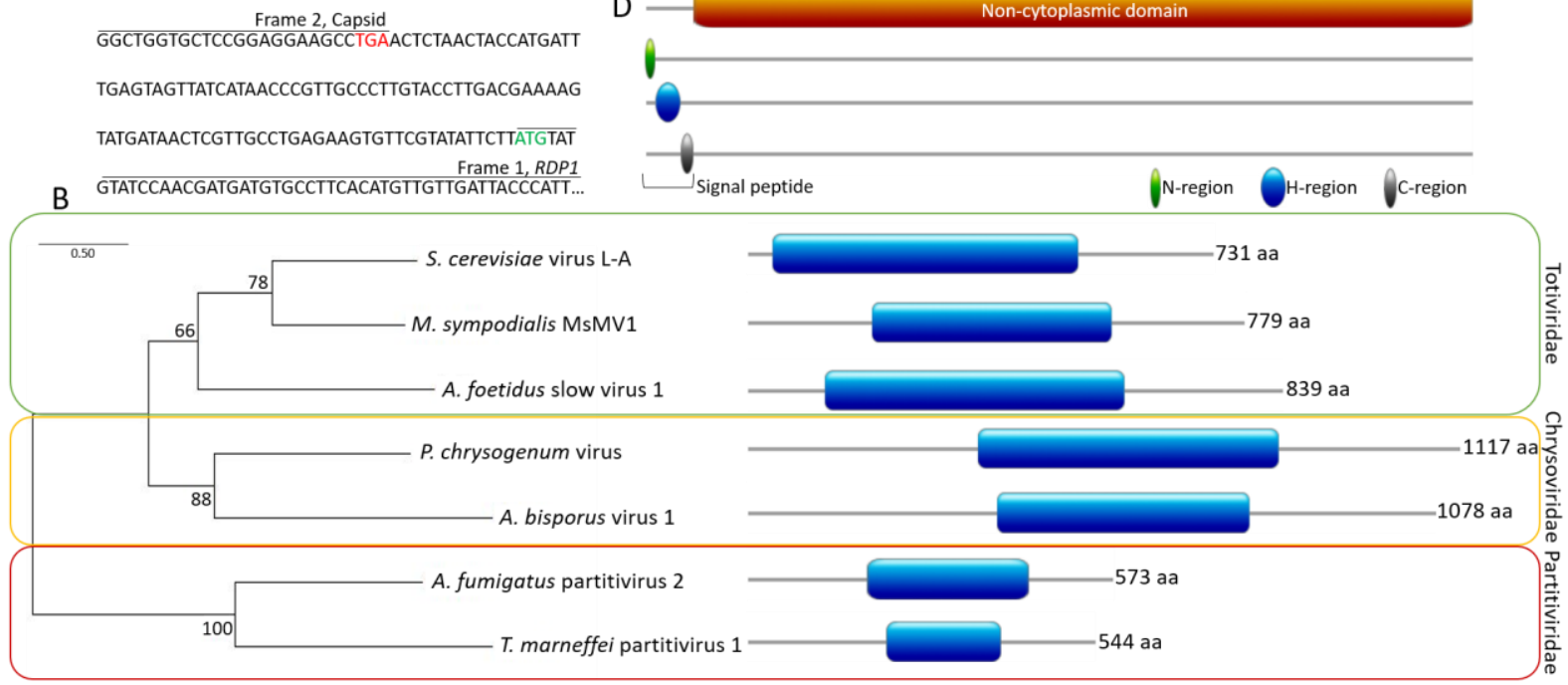

1033

1034

1035

1036

1037

1038

1039

1040

1041

1042

1043

1044

1045

1046

1047 
bioRxiv preprint doi: https://doi.org/10.1101/2019.12.18.880518; this version posted June 11, 2020. The copyright holder for this preprint (which was not certified by peer review) is the author/funder, who has granted bioRxiv a license to display the preprint in perpetuity. It is made available under aCC-BY-NC-ND 4.0 International license.

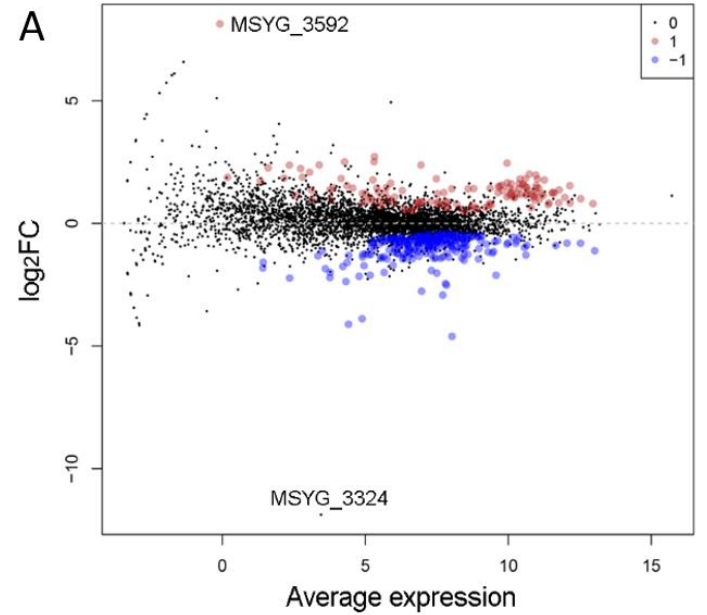

C

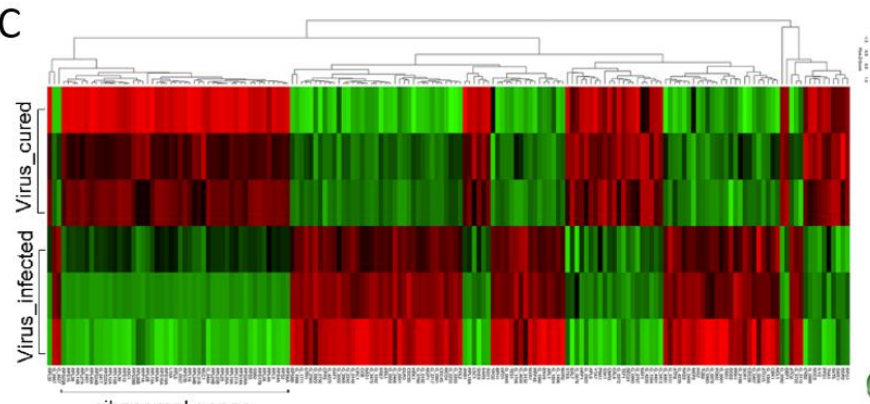

B 50

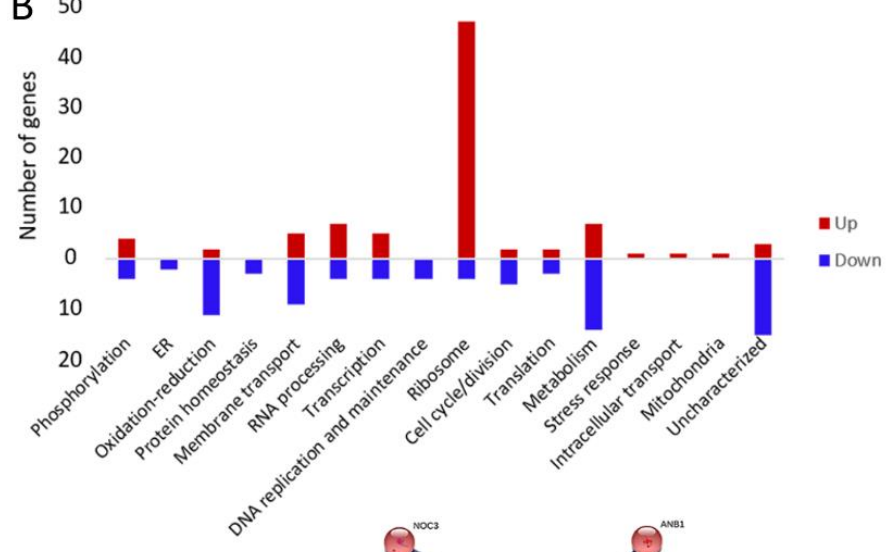

D

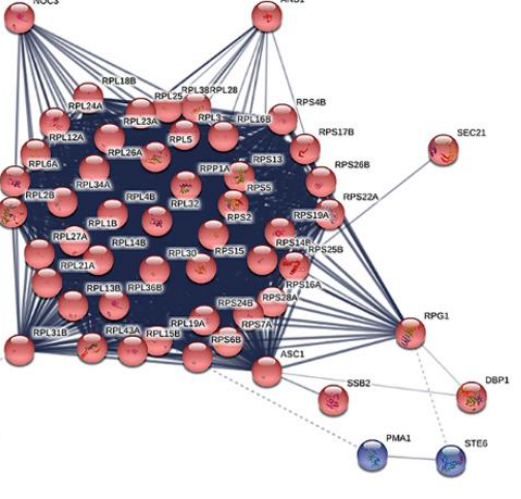


bioRxiv preprint doi: https://doi.org/10.1101/2019.12.18.880518; this version posted June 11, 2020. The copyright holder for this preprint (which was not certified by peer review) is the author/funder, who has granted bioRxiv a license to display the preprint in perpetuity. It is made available under aCC-BY-NC-ND 4.0 International license.

Figure 4
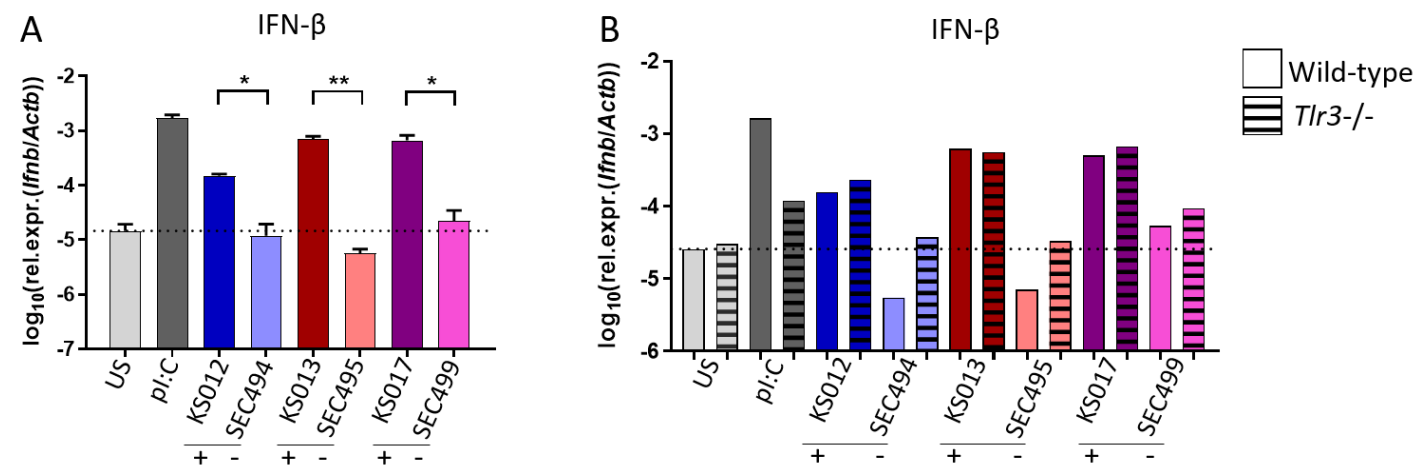